\title{
SUSTAINABLE BUILDING USERS SATISFACTION: EVIDENCE FROM UNIVERSITY BUILDING IN YOLA-NIGERIA
}

\author{
Hyluwa Lelle ${ }^{1}$, Richard Jimoh ${ }^{1 *}$, Luqman Oyewobi ${ }^{2}$, Abdulquadir Bilau $^{1}$, Kabir Ibrahim $^{3}$ \\ ${ }^{1}$ Department of Building, Federal University of Technology, Minna-Nigeria \\ ${ }^{2}$ Department of Quantity Surveying, Federal University of Technology, Minna-Nigeria \\ ${ }^{3}$ Department of Quantity Surveying, University of Ilorin, Ilorin-Nigeria
}

(Received: December 2019 / Revised: December 2019 / Accepted: February 2020)

\begin{abstract}
The quest for sustainable development has placed universities in the central role of sustainability in teaching, research, and application of sustainable principles in the development of their assets. To this end, there was the development of sustainable designs and structures out of many shipping containers within the University environment based in Yola-Nigeria. This study evaluated the satisfaction and comfort of users of the administrative office building through post-occupancy evaluation. The Building Use Studies (BUS) method was adopted to evaluate the performance of the buildings. Data obtained were analysed using the descriptive method of analysis of the BUS survey. Findings show that some sustainable features necessary to ensure the performance of the building, provide comfort and enhance workers' productivity are entrenched in the buildings. All the requisite variables necessary to ensure satisfaction and comfort of the occupants/users of the Buildings are within or above the established benchmark. The lack of personal control of some key variables such as thermal comfort in the physical surrounding is noted to affect some users.
\end{abstract}

Keywords: Built environment; Building Use Studies (BUS); Construction; Sustainable development; University

\section{INTRODUCTION}

The core of all developments that leave pervasive effects on the environment is the creation of the built environment through construction-related activities. The construction industry consumes a major portion of natural resources and generates waste of the same magnitude globally (Dahiru, 2005). According to Gandu (2005), the most ecological crisis which leads to the creation of waste, resources depletion, air pollution, and environmental degradation can directly be associated with various developmental activities within the built environment. Kolawole and Anigbogu (2015) suggested that no building at all is a preeminent way to take care of the environment. Therefore, a balance between waste generation and the built environment can be achieved through the creation of a process that does not hold any form of danger to the ecosystem (Zubairu, 2012).

According to United Nations (1987), sustainable means the use of materials and technology to meet up with the current developmental need of the society without surrendering the capacity of meeting the necessities of the coming generation.

*Corresponding author's email: rosney@futminna.edu.ng, Tel. +234 8036534507

DOI: https://doi.org/10.32783/csid-jid.v3i1.82 
Sustainable development has become vital to cope with limited natural resources and the increasing needs of modern world particularly related to construction industry. For that reason, sustainable construction practice must be adopted. Ali and Al Nsairat (2009) observed that the application of sustainability in construction practice curtails the adverse effect of building and developmental activities on the users and surroundings and also balances the continuous environmental, financial and social health issues. It is also important that energy and its utilization are distinctly emphasised as an important resource and its sustainability is necessary throughout the lifespan of buildings (Thormark, 2002).

Sustainable practices offers a large benefit by reducing energy and water consumption, more standardised spaces and the recyclable material compared to conventional buildings. These characteristics provide value addition to the buildings by reducing its lifecycle costs, enhancing economic value through the improvement of building and organizational marketability, increasing users' output and creating a sustainable community (Ali \& Al Nsairat, 2009). Leadership in Energy and Environmental Design (LEED) proposes components to measure sustainability including sustainability of site, efficient usage of water and energy, recycled materials and resources, and the quality of indoor environment (URA, 2013).

The adaptation of sustainability into design and construction in terms of method and philosophy has remained slow. The disintegrated, complicated and project-based nature of the construction industry poses a hindrance to implementing sustainable construction practices, thereby limiting the application of sustainability (Bygballe \& Swärd, 2014). These barriers making the industry has limited access to the benefits associated with sustainable construction practice including the economic growth, improvement of firms image and status, accomplishing owners request, improvement on statutory structure, gain financial incentive, and maintain good relationship with community (Madu \& Kuei, 2012; Othman, 2011; Suresh et al., 2012).

Khoshbakht, Gou, Xie, He and Darko (2018) study showed that green building users have been more satisfied with building design and facilities management elements such as architecture, facility requirements, building picture, maintenance, meeting room availability, and storage. Conversely, the study identified deficiencies in indoor environmental quality (IEQ) of green buildings, such as noise, ventilation, and artificial lighting. Individual environmental control in non-green buildings positively correlated with satisfaction, but offers insignificant impact on green building satisfaction. However, Park, Loftness and Aziz (2018) contended that buildings' IEQ can have a strong impact on the comfort, efficiency, and safety of the occupants. Postoccupancy assessment (POE) is essential to determine the built environment's IEQ and is usually focused on the quality of thermal, air, visual, and acoustic. As a result of various research methods and interventions, earlier studies have expressed a conflicting body of information about the effect of sustainable buildings on workers and occupant satisfaction (Thatcher \& Milner, 2016). Studies such as Altomonte and Schiavon (2013) and Geng, Ji, Lin and Zhu (Geng et al., 2017) indicated that occupational office experience and environmental satisfaction are affected by various environmental factors such as thermal, visual, acoustic, and air quality, as well as workplace features comprises of anonymity, seating arrangement, cleanliness, and environmental control.

The focus of this paper is on measuring the building's performance through its occupants impressions using Post Occupancy Evaluation (POE) as opposed to environment's physical characteristics (temperature, noise, light). The POE provided an opportunity to investigate the impact of occupant behaviour on the building's performance and its level of comfort and satisfaction. According to Cooper (2001) and Bluyssen, Aries and van Dommelen (2011), Postoccupancy assessment (POE) has been used to assess building efficiency systematically to enhance indoor environmental quality and user satisfaction with thermal, climate, visual and 
acoustic conditions. In order to improve its efficiency, POE information from Auliciems and Szokolay (2012) and Wagner, Gossauer, Moosman, Gropp, and Leonhart (2007) can be used to evaluate operation of the building. It is also useful for regulating the building's internal environment to improve user comfort, well-being and satisfaction. The wider performance factors assessed by a POE will address issues such as use of space, management, environmental impact, and consumption costs (Bordass \& Leaman, 1997). Recently, Sodagar and Starkey (2016) stated that POE also useful as a feedback loop at the design stage to provide input during decision-making process. Fieldson and Sodagar (2017) emphasised that POE has been used frequently in traditional buildings, but limited studies found in specialised buildings especially that adopts sustainability issue.

Stakeholders in construction industry failed to understand the benefits in adopting sustainability into the project. Therefore, identifying enabling factors of sustainability becomes crucial. Studies such as (Iyer-Raninga, Moore, Kashyap, Ridley, and Aandamon (2015) evaluate implementation of sustainable buildings and targeted outcome that can be achieved. Many buildings have focused largely on utility performance or occupants' feedback. Therefore, this study evaluated users' perception on the application of sustainable construction practices in the construction of the administrative building in the University. In conducting the evaluation, the study assessed the building utility performance and occupants' feedback to obtain holistically factors that could engender sustainability.

Leaman (1991) reported that many structures failed to create better environments. In many cases, buildings are not well-designed and create problems for occupants during operation stage. Literature shows that study regarding occupant satisfaction come from the United States and the United Kingdom, and emerging studies come from Asia, especially China (Liu et al., 2018). There is still limited studies from Nigeria on sustainable building user satisfaction. This paper studies elements that gave the workspace environmental satisfaction through post occupancy evaluation and attempt to answer end users satisfaction of completed project.

\section{LITERATURE STUDY}

\subsection{Indoor Environmental Quality, Materials and Resources}

The idea of sustainability in buildings is to provide a sound, comfortable, and beneficial indoor condition by taking into account indoor air quality, ventilation, and thermal comfort, access to acceptable ventilation and daylighting, and efficient control of the acoustical (Pennsylvania, 2013). This sustainability edge can be accomplished by utilization of building materials, sealants, adhesives, finishes and furniture, which do not contain, hold, create or discharge any particulate or gasiform contaminants including unstable carbon-based mixtures unsafe for human wellbeing and healthiness. Adequate ventilation systems will successfully expel or treat indoor contaminants while giving sufficient measures of fresh clean air to users and the compartments within the building. The appliance can screen internal air situation including temperature, dampness and carbon dioxide levels, with the goal that building ventilation systems can react when space settings decrease outside the ideal range.

Designs for the building envelope and overall environmental layout not only adjust air temperature and give sufficient ventilation but also improve natural conditions which influence human thermal comfort and wellbeing, including the mean radiant temperature of inside surfaces, indoor air dampness, interior air speed, and internal air temperature (Cohen-Rosenthal et al., 2000). There are several steps to avoid pollution during construction of the building include limiting the creation and spreading of construction dust and filth, avoid contamination of the building from heating, cooling and ventilation frameworks. Construction materials needs to be free from moist, rotten or mildewed to improve user's satisfaction and to prolong building 
operation. Clients also suggeted to utilize biodegradable and amicable cleaning operators prior to put in new air filters in the HVACs and clean any unclean ductwork and ventilation hardware. This action attempt to cleanse any staying airborne gasiform or particulate contaminants (Pennsylvania, 2013).

Sustainable structures typically limit the use of non-renewable construction materials and different resources through effective engineering, design, planning and construction and efficacious reuse of construction rubbles. It boosts the utilization of recovered content materials, efficient built materials, and asset productive composite. The key system and innovation behind green material and resource is the ability to minimize the quantity of materials and to provide less construction waste. More than $75 \%$ of all waste from construction activities are isolated for reprocessing and used as feedstock later on instead of dump as land filled (Newswire, 2013).

LEED and BREEAM are one of renowned green building certified systems that provide third party verification on buildings pursuing green acknowledgement. Buildings that was designed and considered sustainability techniques will be measured over certain variables or measurements that include energy saving, water effectiveness, $\mathrm{CO} 2$ emission, indoor environment quality, and type of resources (Kibert, 2015). These performance factors require valuations from users to affirm their satisfaction with the improvements made by the buildings.

\subsection{Post Occupancy Evaluation}

Post occupancy evaluation (POE) is an examination of built environment efficiency and adequacy of users interest considering satisfaction of occupants and functionality of space compare to the physical and hierarchical components (Turpin-Brooks \& Viccars, 2006; Zimmerman \& Martin, 2001). POE is performance assessment of a building throughout its life cycle, but mostly carried out during operational stage and not similar to other assessments approach conducted in particular stages of building life cycle (W. F. E. Preiser \& Nascar, 2008; Vischer, 2008; Zimmerman \& Martin, 2001). POE contrasts from other building assessments in four ways (Wolfgang F. E. Preiser, 2003). Firstly, the assessment target is building performance assessment from the users' perspective. Secondly, assessment criterion originates from the specified design criteria. Thirdly, occupants' satisfaction and perception are two fundamental measurement in POE to determine performance of building design. Last, POE can incorporate different issues of environmental functionality and users' psychological and social needs.

POE discusses waste reduction, the sum of money, time completion, energy and resources that needed to have inappropriate buildings. But, some adjustment or even demolishment after completion are required due to the failure in mitigating problems or mistakes in the future. (Hay, R. et al., 2017). There is limited information in the public regarding the actual service performance of building. This information is useful to identify improvements to the benefit of building owners and occupants and to develop baseline data on performance indicators to support the development of building codes, regulations and guidelines (Teasdale-St-Hilaire, 2013). Post occupancy evaluation considers users interest and make sure they gain benefits from building design in regards to work performance (Hay, R. et al., 2017).

Several studies identified elements that not only affect the service performance and indoor conditions in workplaces but also impact staff satisfaction and efficiency (Bottom et al., 1997; Gonzalez et al., 1997; Kincaid, 1994). The identified elements include aesthetics, temperature, noise, air, space, lighting, storage, design layout and circulation, adjacency of space, privacy, project administration process, equipment area, meeting spaces, construction quality, accessibility and ease of usage. Users usually have enough information about the indoor quality 
of a building and its effects on wellbeing and efficiency (Zagreus et al., 2004). Factors that can be evaluated as essential indoor factors in POE discussed as follows.

\subsubsection{Lighting}

Menzies and Wherrett (2005) refers lighting to the availability of natural and artificial lighting in a working environment. It incorporates the quality, concentration and luminance, flexibility in quantity accessible to office-users. There are some aspects such as comfort and productivity of a work environment that influenced by the level of lighting including day lighting, artificial lighting and glare.

\subsubsection{Comfort}

Thermal comfort is basically a subjective reaction or perspective expressed by an individual regarding satisfaction to the thermal condition (Olesen \& Brager, 2004). Thermal comfort is mainly a natural changes from the body's warmth, but sometimes influenced by certain temperature and social factors. There are four parameters that constitute the thermal environment such as air temperature, radiant temperature, humidity and air speed. Other two parameters are more personal including clothing and movement level, or metabolic rate. Individuals might be displeased due to general (entire body) thermal comfort and due to native (partial body) thermal discomfort factors (radiant asymmetry, draft, vertical air temperature distinction, and floor surface temperature). At the moment, no techniques exist for joining the level of unsatisfied individuals because of different factors to give an exact forecast of the number of individuals finding the environment undesirable.

\subsubsection{Air Quality}

Air quality refers to the indoor air quality and subjective to one occupant to anothers (de Dear \& Brager, 1998). The air perceived by occupants as identified by Air Quality Index (IAQ) is "air is stuffy and stale"; "air is not clean"; "bad odour air". The three most commonly recognized sources of air contamination in any building are food, carpet or furniture, and other people. American society of Heating, Refrigerating and Air Conditioning Engineers (ASHRAE) Standard 62.1-2004 characterizes satisfactory air quality as conditions in which over $80 \%$ of users do not express displeasure.

\subsubsection{Acoustics}

Acoustics is a critical quality of any office building design. Noise suggests as one of the most common source of displeasure in workplaces and can create high level of stress for occupants (Jensen et al., 2005). Privacy when trying to communicate reserved information especially in meetings may be greatly influenced with noise and yet, acoustics is given minimal attention during design consideration when compared to ventilation, thermal, other aesthetics and architectural information or engineering considerations. Designers and owners of buildings may not sufficiently comprehend the causes and outcomes of poor acoustical performance. Therefore, it would be important to decide on how users see the acoustical contribution of the environment and what parts of office building design are impacting these observations.

\section{METHODS}

In conducting this study, the international standardised Building Use Studies (BUS) method was adopted to assess building performance through a survey of occupant satisfaction. This study benchmark the investigated building against similar and related buildings. Similar studies 
such as Fieldson and Sodagar (2017), Khoshbakht, Gou, Xie, He and Darko (2018) and Park, Loftness and Aziz (2018) adopted this method.

The questionnaire considers a 7 point of scale and structured to obtain data based on three component parts. The rating starting from 1 as the minimum and 7 as the best to describe parameters such as 'poor' or 'good', 'unsatisfactory' or 'satisfactory', 'very poor' or 'very good', 'uncomfortable' or 'comfortable', 'too little' or 'too much', 'no control' or 'full control'. The questionnaire consist of (1) the occupant's background in relation to the building, (2) characteristics of the building such as the building design, workspace requirement, spatial provision and work area, user needs, safety consideration, availability of rooms and storage area, and (3) overall comfort of users of the building in relation to productivity at work and effect on health and behaviour. The survey also obtained respondents' level of satisfaction or comfort to over forty (40) identified variables regarding light, noise, comfort, temperature, needs and control (see www.busmethodology.org.uk)

The respondents population consist of 168 staff working under four (4) departments in the administrative building and the survey conducted in October 2017 (Sha'ar et al., 2017). Data obtained from the survey were analysed using the descriptive method of analysis of the BUS survey and subsequently presented.

The administrative building as the case study has an approximate gross floor area of $1950 \mathrm{sqm}$ with 25 private offices, 144 workstations and 7 conference rooms to accommodate 200 users. It is made-up of 18 numbers 40 feet $(12 \mathrm{~m}$ long) containers as shown in Figure 1 . The building main entrance facing the east with $10 \mathrm{~m}$ projected canopy against sun rays. The eaves along North and the South walls are designed to prevent direct sun rays, thereby reducing heat. The walls insulated with polyurethane (PU) but finished with upgraded laterite finish. With fixed doubled glazed windows, the building depends on mechanical ventilation using air conditioner, special high-volume low speed (HVLS) fans, and extractor fans for air circulation. The building's thermal comfort and indoor air quality upgraded with Heating, Ventilation and Air Conditioning (HVAC) in addition to the HVLS fans. The HVAC controls the high temperature and air exchanger circulate fresh air and extract contaminated air.

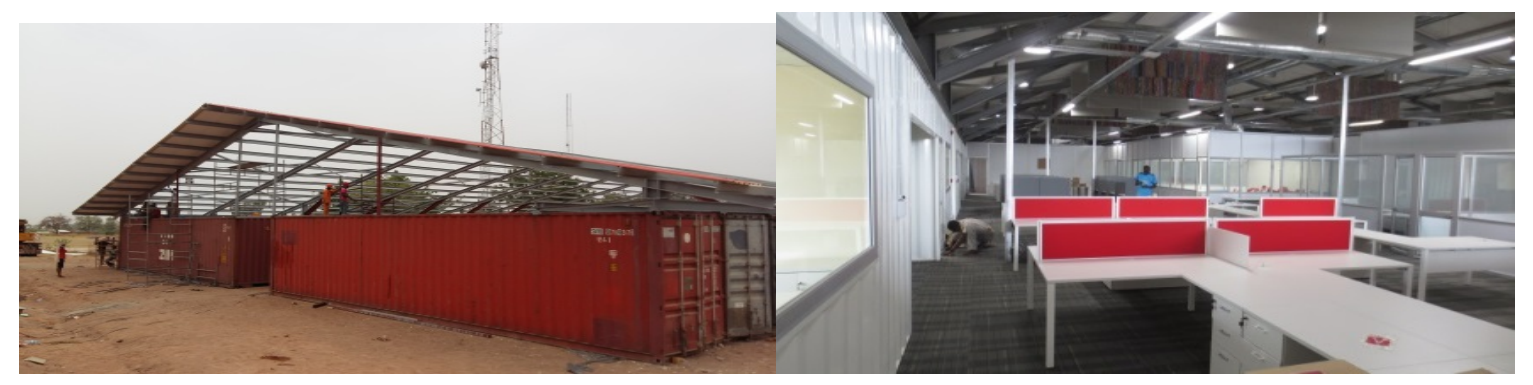

Figure 1 Plates showing the containers and the roofing carcass and the interior (workstations) when completed

\section{RESULTS AND ANALYSIS}

One hundred and twenty-six (126) occupants responded to the survey. There are 82 males and 44 females and $50 \%$ of the occupant were less than 30 years of age. Seventy-two percentage $(72 \%)$ of the respondents not change their behaviour on account of the conditions in the building as shown in Table 1. 
Table 1 Demographic information of the respondents

\begin{tabular}{lcc}
\hline$\quad$ Demographic information & Frequency & $\begin{array}{c}\text { Percentage } \\
\text { (\%) }\end{array}$ \\
\hline Sex & 82 & 65 \\
Male & 44 & 35 \\
Female & & \\
\hline Age & 63 & 50 \\
Under 30 & 63 & 50 \\
$>=30$ & & \\
Worked in the building & 102 & 81 \\
Less than a year & 24 & 19 \\
One year or more & & \\
Worked at present desk/work area & 102 & 81 \\
Less than a year & 24 & 19 \\
One year or more & & \\
\hline Did you change your behaviour because of the conditions in the & & 28 \\
building? & 33 & 72 \\
Yes & 83 & \\
No & & \\
\hline
\end{tabular}

The following are the aspects that were covered in the survey:

The overall building; building design, needs, space, image, safety, cleaning, meeting room availability, storage arrangements, work requirements, furniture, and space.

Comfort; temperature and air quality in different climatic seasons, noise, lighting, comfort overall, productivity at work and health.

Personal Control; of heating, cooling, ventilation, lighting, and noise.

Response to problem; speed of response, effectiveness of response, effect on behaviour and method of travel to work.

Figure 2 shows the summarized result of the overall variables used in analysing the performance of the building using the BUS methodology.

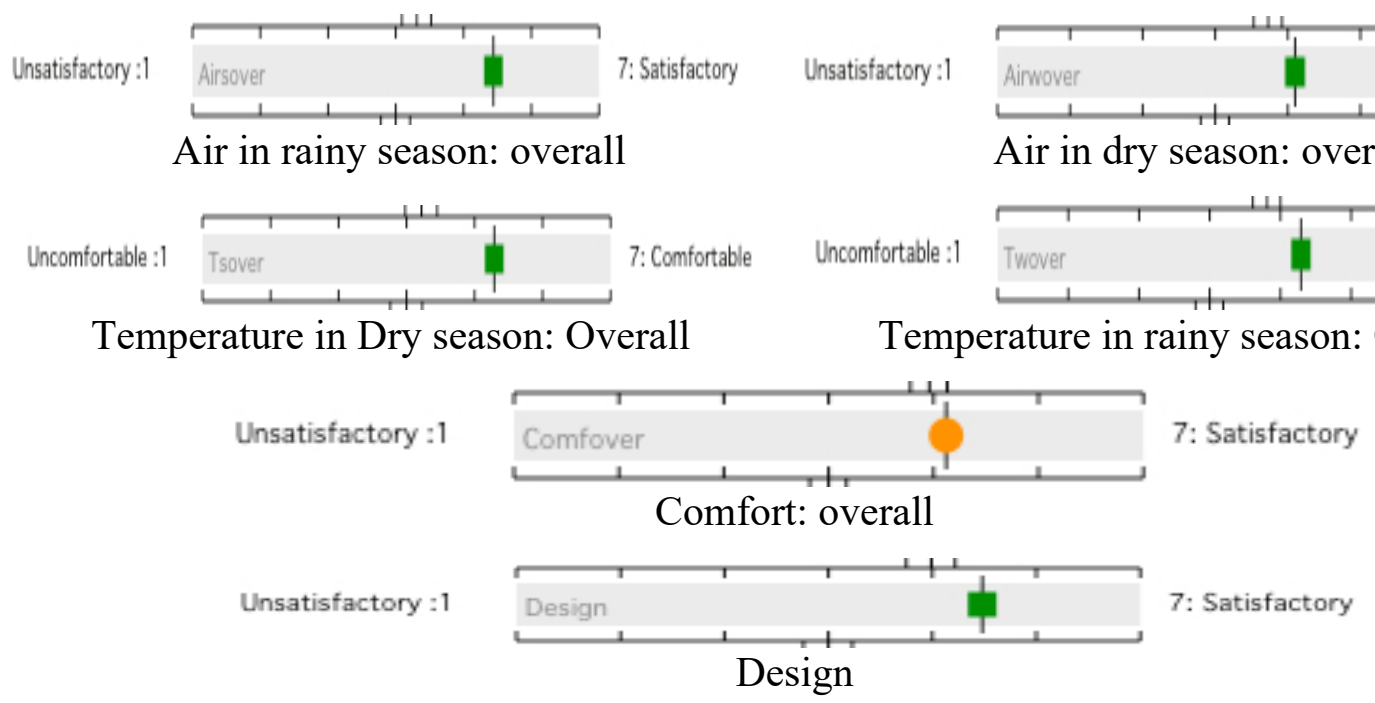




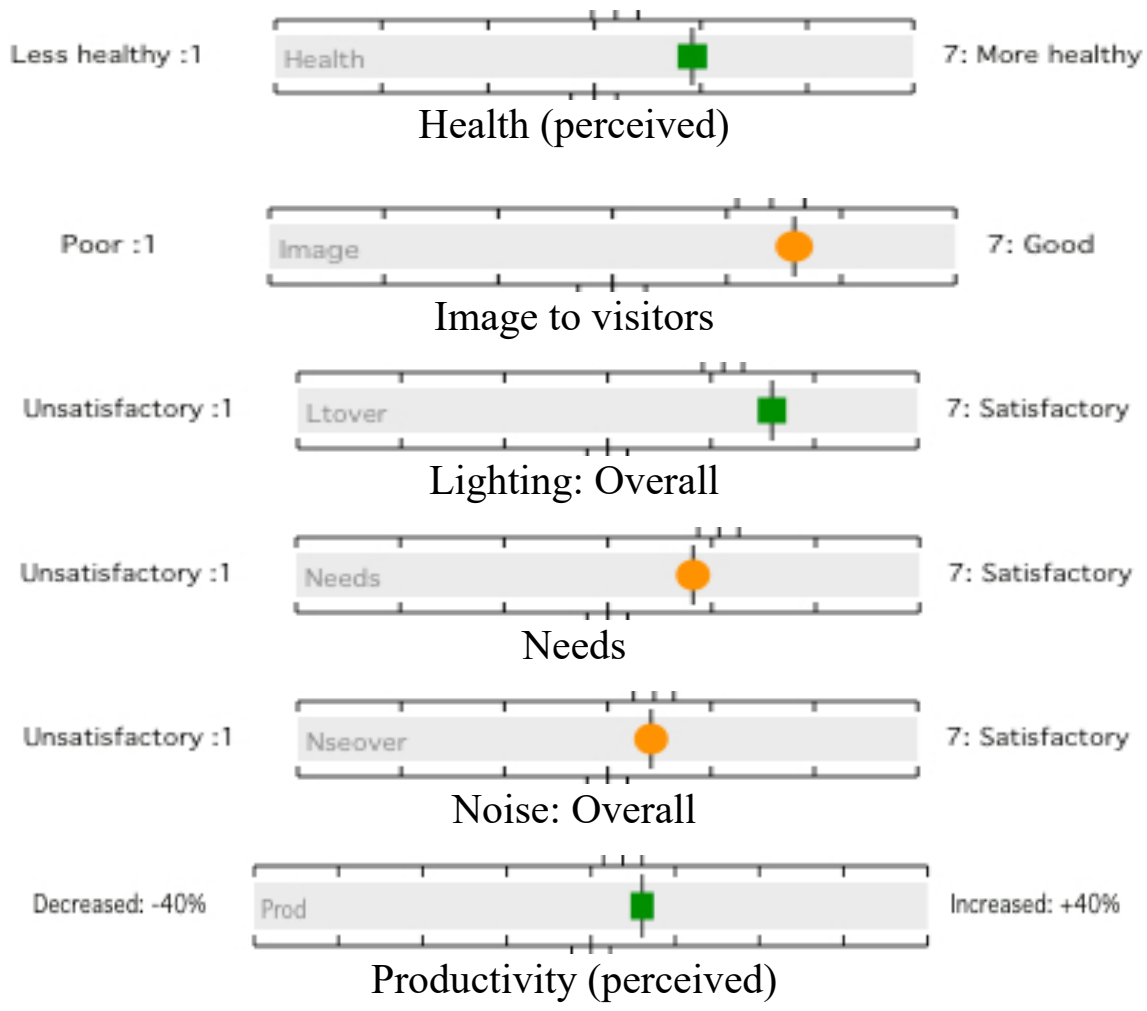

Figure 2 Bus Survey Summary of Overall variables

Figure 2 shows the results of twelve key variables used in the analysis. Each of the slider has three benchmarks indicating lower, mean and upper limits and three shapes with different colours which are; square (green colour), round (amber colour) and diamond (red colour). These colours indicate each test result for a particular variable falls into in relation to the benchmark.

The benchmark where each criterion presented in the questionnaire consist as follows.

Green square shape pointing to the performance of the criteria above the acceptance level or benchmark. These show that users were very satisfied with parameters such as the odourless air in rainy and dry season, temperature overall in dry and rainy season, productivity level from working in the building, furniture, the design, cleaning, effective response to issues, lighting overall etc. Some comments of the occupants including; 'environmentally friendly design', 'great interior design', 'creative and original', 'excellent lighting', 'natural light from the sun which is sufficient', 'satisfied with lighting', 'good environmental condition which enhance productivity'.

The round amber colour, which was established in overall comfort, noise overall, meeting rooms, storage space, control over cooling/heating/noise, image, and needs. On the scale, these parameters were neither on the upper nor lower point benchmark. This indicates that the criteria fell within acceptance level of performance. The occupants were comfortable on the average but were not satisfied with those factors. Comments on some of those parameters including; 'conducive as an office building', 'I am not comfortable because of the smell of food from kitchen', 'comfortable with temperature, lighting and acoustics', 'meeting rooms not meeting departmental need due to large number of staff', 'satisfactory meeting space but narrow circulation space', 'professional needs is averagely met', 'no space for storage of my accessories and working tools', 'students will not enjoy the reception provided', 'working space, circulation and symmetry is very good', 'distraction from colleagues'. 
Red diamond shape clearly shows a failure in that particular feature in the sight of the users due to the failure to meet up the benchmark as performance acceptance level. Some of the factors that fell to make this critical acceptance level include; air (dry/humid) both in dry and rainy season, control of lighting and ventilation, light artificial and natural, noise from colleagues/outside/inside/unwanted and space at desk. This resulted into negative comments from respondents includes; 'need more space around my desk', 'space is too tight', 'space not adequate to accommodate visitors', 'noise from colleagues and those visiting is too much', 'roof makes noise during mid-day due to expansion', 'easy distraction due to open nature which causes noise all over', 'reflection from natural light when it is sunny', 'light from solar tube directly on my desk disturbs me a lot with glare', 'the light is warm white which is not adequate for us to see computer components'.

Other comments made were on things that work well for users, these included:

- Adequate/moderate ventilation neat environment

- Easy access and vision for communication with team members or colleagues during working hours.

- The environment, light, cooling system, set up, furniture, workbench, storage cabinets.

- Maintenance promptness.

Comments made on things that did not work well for the users focused on the open nature of the office, which allowed everyone see each others and cause unnecessary noise. The furniture did not work for some departments and lack of control for AC, ventilation and noise.

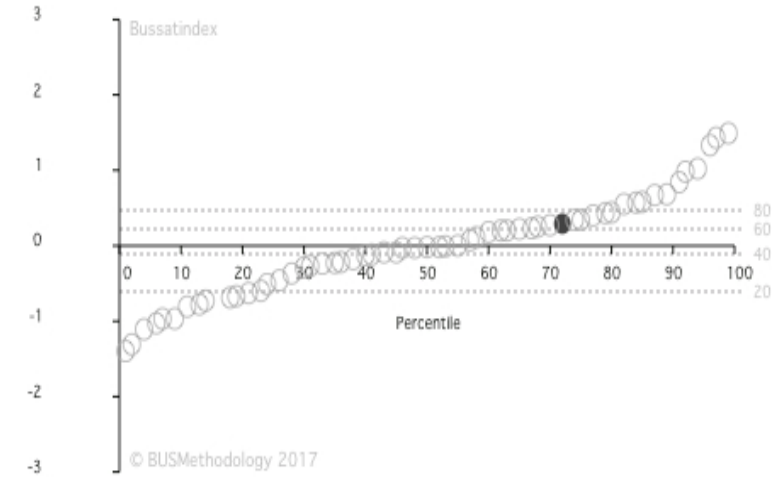

Figure 3 BUS Satisfaction Index

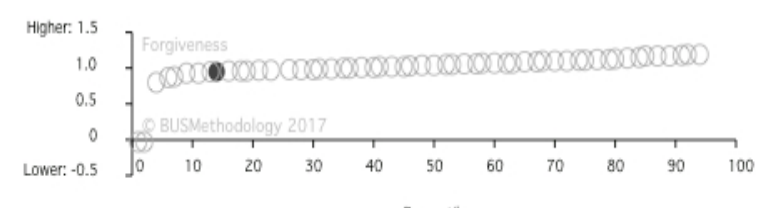

Figure 5 BUS forgiveness Index

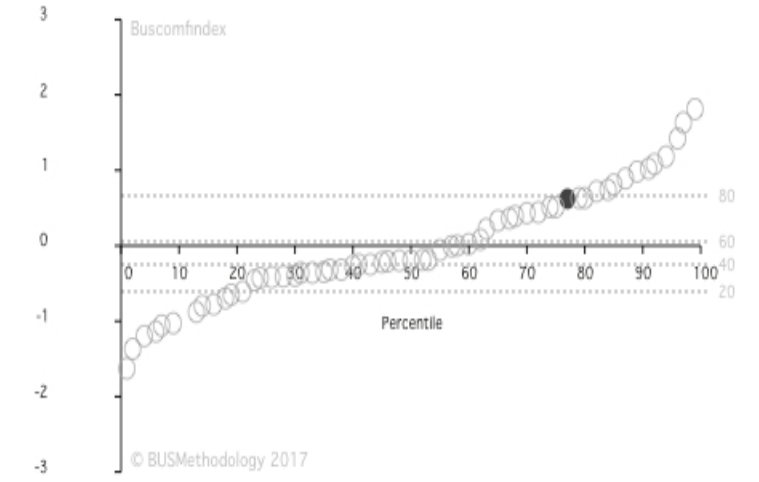

Figure 4 BUS Comfort Index

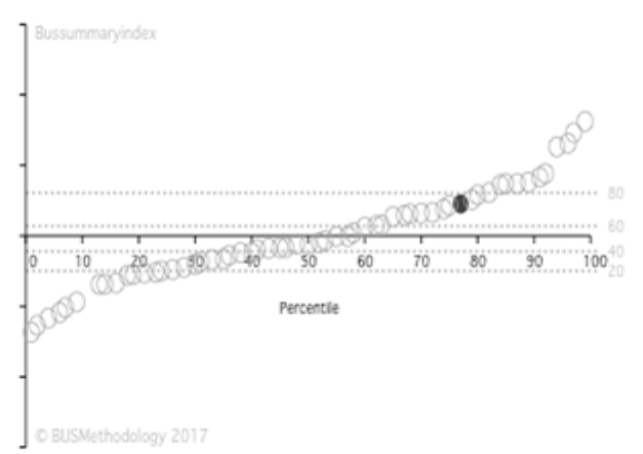

Figure 6 BUS Summary Index

Shaded circle on the scale is the case study (see Figure 3-6) in relation to other buildings analysed using the BUS methodology (over seven hundred buildings analysed with the same method worldwide). Fieldson and Sodagar (2017) asserted that the high level of user control 
over building's function may lead to their convenience and satisfaction. Notwithstanding environmental factors, the users may show willingness to be happy and to forgive other parts of the building that are not working, as they should. Leaman and Bordass (2007) concluded that values greater than 1 means occupants may be more tolerant, or 'forgiving' of certain conditions.

From the scale, the building tends to fall in a satisfactory position when compared to other buildings all over the world, which signifies users' level satisfaction. However, Leaman (2002) cautioned that there is a thorny "context control" problem faced by a case study. Due to different operating conditions that are prevalent, it is most times difficult to draw firm conclusion from buildings even if they seem to be the same, therefore, there is the need to be cautious while drawing conclusion.

\section{DISCUSSIONS}

The BUS methodology adopted for the survey, with objective to identify the level of occupant satisfaction and comfort which Huizenga et al. (1998) regarded as one of the best technique to establish the level of satisfaction of a facility. The building carries some sustainable features which Wilkinson, James and Reed (2009) viewed as conditions necessary for comfort and enhanced productivity of an office building. Other scholars also highlighted these criteria as vital for any sustainable office including temperature, ventilation, noise, lighting, comforts, needs, and control (Abbaszadeh et al., 2006; Edwards, 2006; Roulet et al., 2006; Zagreus et al., 2004).

The results shows the satisfaction and comfort level of the occupants. These results confirmed the study of Frontczak et al. (2012) which emphasised features such as thermal, acoustic, air quality, finishes and other features of the internal environment in regard to circulation, space planning, layout, personal controls and cleaning have significant effects on the satisfaction of occupants in an office setting. The findings of this research showed that temperature and air both in rainy and dry seasons which fell above the benchmark provide thermal satisfaction for the occupants.

The survey showed issue regarding the lack of personal control affected some users, as noted by the Scottish Government (2008), that the mental health, wellbeing and comfort of people are greatly influenced by their physical surrounding. Comments like "I have to use sweater due to the coldness within the building or sometimes goes outside under the sun to get some heat", arose from the users' on lack of control for thermal comfort. Bordass and Leaman (1997) emphasised that it is important that the working group is able to effectively control its physical conditions. Invariably, the area used by any working group should be subject environmental controls that will suit their needs. Therefore, lighting, heating, cooling and ventilation should all have a degree of direct control from within the working group's occupied space. Such control regimes are rarely found in many buildings, especially those where multi-functional space is provided.

There are issues affecting users such as limited space and exposed working cubicles which led to noise and constant distractions. Subsequently, the lacked of control of lighting causes direct glare to users, fixed windows limiting access to fresh air, and central control of HVAC with constant temperature suggests uncomfortable cooling mechanism. There are privacy issue due to the use of curtain walls and glass partitions, and flexibility issue in office spaces like meeting rooms.

In addition, negative comments recorded in regards to workstation layout and furniture selection which affected the productivity of the occupants. This result in line with the works of 
Meyer (1999) and Vischer (2008) which insisted that self-confidence, well-being and productivity of users can be improved by how gratifying the workplace is in relation with the type of work and the physical environment. This is supported by comments from respondents including "Lack of adequate space, proper tables, cabinets for computer parts not provided, minor things keep missing", "Lack of workbench, cabinets or storage for excess laptops, poor illumination", "No privacy for students who needs personal talk", "Reception area for students is not big enough, space allocated to us is not enough". Based on Figures 3-6, in comparison to other buildings, it can be seen that the variables examined are either within the benchmark or above the benchmark; however, areas of improvement especially from the comments of the occupants have to be taking into consideration.

\section{CONCLUSION}

The POE survey conducted largely showed that the users were satisfied with the containerized building. The variables analysed include but not limited to temperature, lighting, control, noise, design, needs, and image, which found to be within or above the benchmark. The result of the POE indicated the comfort and acceptance levels of the building were above satisfactory level. The result also found noticeable areas of improvements such as controls, furniture arrangements, needs, meeting rooms, and window types.

In view of the findings made from this study, the following recommendations can be drawn. Users should be involved in the design and planning to generate satisfactory result from users' perspective. Therefore, engaging potential users play significant role to achieve sustainable outcome for building development. Furthermore, control of variables such as lighting, ventilation, cooling/heating, temperature, and noise should be taken into account when designing office building to significantly countribute productivity factor and users wellbeing.

This study has some limitation that should be considered in future research development. As, every buildings have different geographical locations, climate condition and building specifications and requirements, it is suggested that future studies taking into account buildings across different countries for comparison and suggests alternative reccommendation.

\section{ACKNOWLEDGEMENT}

$\mathrm{Mr}$ Adrian Leaman of BUS, United Kingdom is acknowledged for the design of the questionnaire and the analysis that resulted thereof.

\section{REFERENCES}

Abbaszadeh, S., Zagreus, L., Lehrer, D., \& Huizenga, C. (2006). Occupant satisfaction with indoor environmental quality in green buildings. HB 2006 - Healthy Buildings: Creating a Healthy Indoor Environment for People, Proceedings, 3, 365-370.

Ali, H. H., \& Al Nsairat, S. F. (2009). Developing a green building assessment tool for developing countries - Case of Jordan. Building and Environment, 44(5), 1053-1064. https://doi.org/10.1016/j.buildenv.2008.07.015

Altomonte, S., \& Schiavon, S. (2013). Occupant satisfaction in LEED and non-LEED certified buildings. Building and Environment, 68, 66-76. https://doi.org/10.1016/j.buildenv.2013.06.008

Ametepey, S. O., \& Ansah, S. K. (2015). Impacts of Construction Activities on the Environment: the Case of Ghana. Academia, 5(3), 18-27. https://www.academia.edu/6046663/Impacts_of_Construction_Activities_on_the_Environ ment The_Case_of_Ghana

Anonymous. (2008). Health in Scotland 2007: annual report of the chief medical officer. 
http://www.scotland.gov.uk/Publications/2007/11/15135302/10

Bluyssen, P. M., Aries, M., \& van Dommelen, P. (2011). Comfort of workers in office buildings: The European HOPE project. Building and Environment, 46(1), 280-288. https://doi.org/10.1016/j.buildenv.2010.07.024

Bordass, W., \& Leaman, A. (1997). Future buildings and their services. Building Research \& Information, 25(4), 190-195. https://doi.org/10.1080/096132197370309

Bottom, C., Mcgreal, S., \& Heaney, G. (1997). Evaluating office environments using tenant organization perceptions. $\quad$ Facilities, 15(7-8), 195-203. https://doi.org/10.1108/02632779710168236

Bygballe, L. E., \& Swärd, A. (2014). Implementing lean construction: A practice perspective. 22nd Annual Conference of the International Group for Lean Construction: Understanding and Improving Project Based Production, IGLC 2014, 3-14.

Cassen, R. H. (1987). Our common future: report of the World Commission on Environment and Development. In International Affairs (Vol. 64, Issue 1). https://doi.org/10.2307/2621529

Cohen-Rosenthal, E., Schlarb, M., Thorne, J., Serchuk, A., \& Bradley, D. (2000). Build it Right: Cleaner Energy for Better Buildings.

Cooper, I. (2001). Post-occupancy evaluation - Where are you? Building Research and Information, 29(2), 158-163. https://doi.org/10.1080/09613210010016820

Dahiru, D. (2005). Measures of Ensuring Sustainability in the Nigerian Construction Industry. Conference Proceedings of the 2nd National Conference Tagged Towards a Sustainable Built Environment.

de Dear, R., \& Brager, G. S. (1998). Thermal Adaptation in the Built Environment: a Literature Review. Energy and Buildings, 27(1), 83-96. https://doi.org/10.1016/j.enbuild.2013.06.009.Keywords

Edwards, B. (2006). Benefits of green offices in the UK: Analysis from examples built in the 1990s. In Sustainable Development (Vol. 14, Issue 3, pp. 190-204). https://doi.org/10.1002/sd.263

Fieldson, R., \& Sodagar, B. (2017). Understanding user satisfaction evaluation in low occupancy sustainable workplaces. Sustainability (Switzerland), 9(10). https://doi.org/10.3390/su9101720

Frontczak, M., Schiavon, S., Goins, J., Arens, E., Zhang, H., \& Wargocki, P. (2012). Quantitative relationships between occupant satisfaction and satisfaction aspects of indoor environmental quality and building design. Indoor Air, 22(2), 119-131. https://doi.org/10.1111/j.1600-0668.2011.00745.x

Gandu, Y. J. (2005). Environmental Management Tools for Sustainable Development. Proceedings of the National Conference towards a Sustainable Built Environment.

Geng, Y., Ji, W., Lin, B., \& Zhu, Y. (2017). The impact of thermal environment on occupant IEQ perception and productivity. Building and Environment, 121, 158-167. https://doi.org/10.1016/j.buildenv.2017.05.022

Gonzalez, M. S. R., Fernandez, C. A., \& Cameselle, J. M. S. (1997). Empirical validation of a model of user satisfaction with buildings and their environments as workplaces. Journal of Environmental Psychology, 17(1), 69-74. https://doi.org/10.1006/jevp.1996.0040

Hay, R., Bradbury, S., Dixon, D., Martindale, K., Samuel, F., \& Tait, A. (2017). Pathways to $P O E$, value of architects.

Jensen, K. L., Arens, E., \& Zagreus, L. (2005). Acoustical Quality in Office Workstations , As Assessed By Occupant Surveys. Indoor Air: 10th International Conference on Indoor Air Quality and Climate, 2401-2405.

Khoshbakht, M., Gou, Z., Xie, X., He, B., \& Darko, A. (2018). Green building occupant satisfaction: Evidence from the Australian higher education sector. Sustainability 
(Switzerland), 10(8). https://doi.org/10.3390/su10082890

Kibert, C. (2015). Sustainable Development and Sustainable Construction. In Sustainable Construction - Green Building Design and Delivery.

Kincaid, D. G. (1994). Measuring Performance in Facility Management. In Facilities (Vol. 12, Issue 6, pp. 17-20). https://doi.org/10.1108/02632779410060265

Leaman, A. (1991). What is a Building for?: Part I. Facilities, 9(10), 13-16. https://doi.org/10.1108/EUM0000000002162

Liu, Y., Wang, Z., Lin, B., Hong, J., \& Zhu, Y. (2018). Occupant satisfaction in Three-Starcertified office buildings based on comparative study using LEED and BREEAM. Building and Environment, 132, 1-10. https://doi.org/10.1016/j.buildenv.2018.01.011

Madu, C. N., \& Kuei, C. H. (2012). Introduction to sustainability management. In Handbook of Sustainability Management (pp. 1-22). https://doi.org/10.1142/9789814354820_0001

Menzies, G. F., \& Wherrett, J. R. (2005). Windows in the workplace: Examining issues of environmental sustainability and occupant comfort in the selection of multi-glazed windows. Energy and Buildings, 37(6), 623-630. https://doi.org/10.1016/j.enbuild.2004.09.012

Meyer, H. (1999). Fun for Everyone. In Journal of Business Strategy (Vol. 20, Issue 2, pp. 1317). https://doi.org/10.1108/eb039989

Moore, T., Moore, T., \& Ridley, I. (2015). Beyond buildings : holistic sustainable outcomes for university buildings. 15th International Australasian Campuses towards Sustainability, November.

Newswire, P. R. (2013). World Green Building Trends SmartMarket Report: Business Imperative and Market Demand Driving Green Building Growth. In NY-McGrawHillConst.

Olesen, B. W., \& Brager, G. S. (2004). A better way to predict comfort. ASHRAE Journal, 46(8), 20-28.

Othman, A. A. E. (2011). Lean Principles as a Strategic Option for Delivering Innovative Sustainable Construction Projects: A Client Value Driven Approach. The Sixth Built Environment Conference Johannesburg South Africa 31 July--2 August 2011, 17.

Park, J., Loftness, V., \& Aziz, A. (2018). Post-occupancy evaluation and IEQ measurements from 64 office buildings: Critical factors and thresholds for user satisfaction on thermal quality. Buildings, 8(11). https://doi.org/10.3390/buildings8110156

Pennsylvania, G. (2013). What is Green Building? Fundamental Principles of Green Building and Sustainable Design. In Building Green in Pennsylvania. http://www.epa.gov/statelocalclimate/documents/pdf/12_8_what_is_green_GGGC.pdf

Preiser, W. F. E., \& Nascar, J. L. (2008). Assessing Building Performance: Its Evolution From Post-Occupancy Evaluation. Archnet-IJAR - International Journal of Architectural Research, 2(1), 84-99. https://doi.org/10.26687/archnet-ijar.v2i1.179

Preiser, Wolfgang F. E. (2003). Continuous quality improvement through post-occupancy evaluation feedback. Journal of Corporate Real Estate, 5(1), 42-56. https://doi.org/10.1108/14630010310811993

Roulet, C. A., Johner, N., Foradini, F., Bluyssen, P., Cox, C., De Oliveira Fernandes, E., Müller, B., \& Aizlewood, C. (2006). Perceived health and comfort in relation to energy use and building characteristics. Building Research and Information, 34(5), 467-474. https://doi.org/10.1080/09613210600822279

Sha'ar, K. Z., Assaf, S. A., Bambang, T., Babsail, M., \& Fattah, A. M. A. El. (2017). Designconstruction interface problems in large building construction projects. International Journal of Construction Management, 17(3), 238-250. https://doi.org/10.1080/15623599.2016.1187248

Sodagar, B., \& Starkey, D. (2016). The monitored performance of four social houses certified 
to the Code for Sustainable Homes Level 5. Energy and Buildings, 110, 245-256. https://doi.org/10.1016/j.enbuild.2015.11.016

Suresh, S., Bashir, A. M., \& Olomolaiye, P. O. (2012). A protocol for lean construction in developing countries. In G. Ofori (Ed.), Contemporary Issues in Construction in Developing Countries (pp. 376-405). Spon Press. https://doi.org/10.4324/9780203847350

Teasdale-St-Hilaire, A. (2013). Post-occupancy evaluation framework for multi-unit residential buildings. Thermal Performance of the Exterior Envelopes of Whole Buildings - 12th International Conference.

Thatcher, A., \& Milner, K. (2016). Is a green building really better for building occupants? A longitudinal evaluation. Building and Environment, 108, 194-206. https://doi.org/10.1016/j.buildenv.2016.08.036

Thormark, C. (2002). A low energy building in a life cycle - Its embodied energy, energy need for operation and recycling potential. Building and Environment, 37(4), 429-435. https://doi.org/10.1016/S0360-1323(01)00033-6

Turpin-Brooks, S., \& Viccars, G. (2006). The development of robust methods of post occupancy evaluation. In Facilities (Vol. 24, Issues 5-6, pp. 177-196). https://doi.org/10.1108/02632770610665775

URA. (2013). Green Development Resources for Commercial Development. www.ura.org

Vanos, J. K., Warland, J. S., Gillespie, T. J., \& Kenny, N. A. (2012). Thermal comfort modelling of body temperature and psychological variations of a human exercising in an outdoor environment. International Journal of Biometeorology, 56(1), 21-32. https://doi.org/10.1007/s00484-010-0393-2

Vischer, J. C. (2008). Towards an environmental psychology of workspace: How people are affected by environments for work. Architectural Science Review, 51(2), 97-108. https://doi.org/10.3763/asre.2008.5114

Wagner, A., Gossauer, E., Moosmann, C., Gropp, T., \& Leonhart, R. (2007). Thermal comfort and workplace occupant satisfaction-Results of field studies in German low energy office $\begin{array}{lllll}\text { buildings. } & \text { Energy }\end{array}$ https://doi.org/10.1016/j.enbuild.2007.02.013

Wilkinson, S., James, K., \& Reed, R. (2009). Delivering sustainability through the adaptive reuse of commercial buildings : the Melbourne CBD challenge. Proceedings of the Pacific Rim Real Estate Society 15th Annual Conference, 1-19. https://doi.org/10.1675/15244695(2008)31

Zagreus, L., Huizenga, C., Arens, E., \& Lehrer, D. (2004). Listening to the occupants: A Webbased indoor environmental quality survey. Indoor Air, Supplement, 14(8), 65-74. https://doi.org/10.1111/j.1600-0668.2004.00301.x

Zimmerman, A., \& Martin, M. (2001). Post-occupancy evaluation: Benefits and barriers. Building Research and Information, 29(2), 168-174. https://doi.org/10.1080/09613210010016857

Zubairu, S. . (2012). The Importance of Evaluation and Sustainability in the Built Environment. Proceedings of the 4th West Africa Built Environment Research (WABER) Conference. 